\title{
Social impact evaluation of tea production using social life cycle assessment (s-lca) method in Cameron Highlands, Pahang, Malaysia
}

\begin{abstract}
Commercial convention of tea production and plantation at the largest scale in this country has shown an escalation year by year, together with the high demand for tea products in the Malaysian market. This may have a direct social impact throughout the life cycle of tea production. Thus, this research sought to identify the social impacts from the overall process of tea production. This study used the Social Life Cycle Assessment (S-LCA) involving descriptive analysis by assessing the social impacts associated with the stakeholders of tea production using three sets of questionnaires. The studies were conducted at one of the highest tea production companies in Cameron Highlands, Malaysia. The findings of the stakeholders showed a good level of satisfaction because there was no significant negative effect. Overall, the social aspects of the tea production met the required criteria in terms of social significance. However, there were some social aspects that can be improved by the factory in the future such as health and safety, discrimination, job opportunity and local community involvement.
\end{abstract}

Keyword: Social Life Cycle Assessment (S-LCA); Job satisfaction; Job discrimination; Social security; Safe and healthy living condition 